\title{
PROFESSORES: SUJEITOS DE SUA FORMAÇÃO
}

Flávia Maria Albertino

Universidade do Oeste Paulista - UNOESTE, Presidente Prudente, SP, E-mail: fmalbertino@hotmail.com

\section{RESUMO}

A formação docente tem se tornado uma questão de grande relevância e um tema desafiador diante da complexidade e da diversidade presentes no contexto atual da educação. $O$ objetivo deste estudo foi analisar o professor como sujeito da sua própria formação e refletir a identidade docente; compreender as práticas coletivas / colaborativas. A metodologia constou de uma abordagem qualitativa abrangendo-se de estudos bibliográficos com autores renomados, utilizando capítulos de livro, tese, artigo publicado em periódico e trabalho aceito em evento. Os resultados foram a importância de considerar o professor como sujeito em sua própria formação e com identidade docente, num processo de auto formação e de reelaboração dos saberes iniciais. Saberes que vão se constituindo a partir de uma reflexão na e sobre a prática. Constatou-se, que os professores precisam ser vistos e ouvidos como sujeitos integrais e pensantes no processo de formação e não como objetos dela.

Palavras-chave: Professor como sujeito, Formação, Identidade docente, Práticas coletivas, Práticas colaborativas.

\section{TEACHERS: TRAINING YOUR SUBJECTS}

\begin{abstract}
Teacher training has become a matter of great importance and a challenging issue given the complexity and diversity present in the current context of education. The aim of this study was to analyze the teacher as the subject of his own training and reflect the teaching identity; understand the collective / collaborative practices. The methodology consisted of a qualitative approach covering up of bibliographic studies with renowned authors, using book chapters, thesis, article published in a journal and work accepted at the event. The results were the importance of considering the teacher as a subject in their own training and teaching identity, a process of selftraining and re-elaboration of the initial knowledge. Knowledge that are constituted from a reflection in and about the practice. It was found that teachers need to be seen and heard as whole and thinking subjects in the process of formation and not as objects of it.
\end{abstract}

Keywords: Teacher as a subject, training, teacher identity, collective practices, collaborative practices. 


\section{INTRODUÇÃO}

A formação docente tem se tornado uma questão de grande relevância e um tema desafiador diante da complexidade e da diversidade presentes no contexto atual da educação. Os implementadores de cursos de formação continuada visam o domínio de novos conhecimentos e mudança na prática pedagógica (em sua postura e forma de agir), oferecendo informações ou conteúdos.

Essa concepção, particularmente intelectual, não percebe que os professores são indivíduos, sujeitos que vão produzindo sentidos em seus processos de aprender e de ensinar, ou seja, sujeitos de sua formação, nos quais se constituem seus ensejos sociais e afetivos, seus pensamentos e suas emoções.

É preciso ver os professores não como seres abstratos, ou essencialmente intelectuais, mas como seres sociais, com suas identidades pessoais e profissionais, imersos numa vida grupal na qual partilham uma cultura, derivando seus conhecimentos, valores e atitudes dessas relações, com base nas representações constituídas nesses processos que é, ao mesmo tempo, social e intersubjetivo (GATTI, 2003, p. 196).

Os professores precisam ser vistos e ouvidos como sujeitos integrais e pensantes. Portanto, abordar a formação docente respeitando-o/a como sujeito pressupõe também a defesa de suportes para que esse indivíduo possa exercer seu papel social.

Assim, este artigo teve como objetivo analisar o professor como sujeito da sua própria formação e refletir a identidade docente; compreender as práticas coletivas / colaborativas.

A justificativa para essa pesquisa se situa a partir de contribuir para o aprimoramento do professor, proporcionando uma ação-reflexão-ação do processo de formação e dos saberes dos professores.

Pretende-se com essa reflexão contribuir para uma melhor compreensão do que o professor pode e deve fazer para enfrentar os desafios atuais e a melhoria de sua prática docente.

\section{METODOLOGIA}

A pesquisa foi desenvolvida por meio de uma abordagem qualitativa abrangendo-se de estudos bibliográficos com o objetivo de explicitar os aspectos teóricos da temática: Professores: sujeitos de sua formação, com autores renomados, os quais contribuíram para reflexões e discussões enriquecedoras sobre o professor como sujeito da sua própria formação, a identidade docente e compreender as práticas coletivas / colaborativas.

A pesquisa qualitativa diferencia-se pelo olhar e atitude do pesquisador, que procura desenvolver compreensões e não explicações. Ou seja, não pretende responder questões do tipo: "Por que?", já que esse modo de colocar a pergunta implica em buscar as relações de causalidade. Tampouco se apoia numa teoria já construída para servir de base para comprovações (BOGDAN e BIKLEN, 1994 apud ANASTÁCIO, 2006, p. 196).

Em relação à pesquisa bibliográfica, Gil (2010, p. 46) afirma que: “A principal vantagem da pesquisa bibliográfica reside no fato de permitir ao investigador a cobertura de uma gama de fenômenos muito mais ampla do que aquela que poderia pesquisar diretamente [...]".

Os materiais encontrados foram heterogêneos, na forma de capítulos de livro, tese, artigo publicado em periódico e trabalho aceito em evento (produções que são previamente avaliadas por comissões de especialistas). Com um total de dezenove (19) materiais consultados, porém, onze (11) foram selecionados para análise e utilizados nesta pesquisa. 


\section{RESULTADOS}

Reconsiderando a formação dos professores, com base na análise da prática pedagógica, Pimenta (1999) constata o aparecimento da questão dos saberes como um dos aspectos considerados nos estudos sobre a identidade da profissão do professor. $\mathrm{O}$ autor parte do fato de que:

A identidade é construída a partir da significação social da profissão; da revisão constante dos significados sociais da profissão; da revisão das tradições. Mas também da reafirmação das práticas consagradas culturalmente e que permanecem significativas. Práticas que resistem a inovações porque prenhes de saberes válidos às necessidades da realidade. Do confronto entre as teorias e as práticas, da análise sistemática das práticas à luz das teorias existentes, da construção de novas teorias (p. 19).

Desse modo, resgata a importância de considerar o professor como sujeito em sua própria formação, num processo de auto formação, de reelaboração dos saberes iniciais em defrontação com sua prática vivenciada. Assim, seus saberes vão se constituindo, a partir de uma reflexão na e sobre a prática. Essa tendência reflexiva vem-se apresentando como um novo paradigma na formação de professores, sedimentando uma política de desenvolvimento pessoal e profissional dos professores e das instituições escolares.

Segundo Silva (1997), os estudos educacionais conduziram, a partir do final dos anos de 1980, novos conceitos no que tange o trabalho docente. Salienta que as novas abordagens de pesquisa passaram a reconhecer o professor como sujeito de um saber e de um fazer, fazendo surgir a necessidade de se investigarem os saberes de referência dos professores sobre suas próprias ações e pensamentos:

a análise dos valores e princípios de ação que norteiam o trabalho dos professores pode trazer novas luzes sobre nossa compreensão acerca dos fundamentos do trabalho docente, seja no sentido de desvendar atitudes e práticas presentes no dia-a-dia das escolas que historicamente foram ignoradas pela literatura educacional (e talvez possam trazer contribuições para o trabalho e a formação de professores (p. 3).

Considerando a sabedoria e experiência dos professores e estes como sujeitos de sua formação com identidade docente e não como objetos Imbernón (2010, p.77) afirma que "A formação continuada do professor passa pela condição de que este vá assumindo uma identidade docente, o que supõe ser sujeito da formação e não objeto dela, mero instrumento maleável e manipulável nas mãos dos outros".

O processo de formação continuada que tem a prática como ponto de partida e de chegada, permite ao professor desenvolver uma sólida formação profissional. O professor torna-se um protagonista do seu desenvolvimento profissional e de sua formação, deve levar em conta o estudo da sua própria prática, como um dos meios constitutivos da construção de novos saberes profissionais. Dessa maneira verifica-se a superação da dicotomia entre teoria e prática, assim como as políticas públicas descontextualizadas das necessidades relativas ao ensino e da escola.

Para além de se compreender os processos de desenvolvimento pessoal e profissional do professor, é contemplá-lo como detentor de uma profissão na qual o próprio sujeito histórico é capaz de produzir o seu próprio ofício. O desafio contemporâneo, segundo NÓVOA (1995, p. 27) está na valorização de "[...] paradigmas de formação que promovam a preparação de professores reflexivos, que assumam a responsabilidade do seu próprio desenvolvimento profissional e que participem como protagonistas na implementação das políticas educativas". 
Nesse contexto, demanda-se como necessário e imprescindível, a mudança e a inovação das práticas escolares, não mais como no princípio da racionalidade técnica, que estabelece como alguns princípios, a tarefa de alguns que pensam e outros que executam a prática docente. Assim, para Imbernón:

No entanto, tal situação não deve predominar no futuro da formação continuada, mas, sim, os professores devem assumir a condição de serem sujeitos da formação, compartilhando seus significados, com a consciência de que todos somos sujeitos quando nos diferenciamos trabalhando juntos, e desenvolvendo uma identidade profissional (o eu pessoal e coletivo que nos permite ser, agir e analisar o que fazemos), sem ser um mero instrumento nas mãos de outros. (2010, p.78)

Portanto, com a consciência da subjetividade os professores passarão a serem sujeitos de sua formação. Conforme Imbernón (2010, p. 80) “[...] O domínio da formação passará a fazer parte da profissão, se os professores quiserem ser os protagonistas de sua formação e de seu desenvolvimento profissional".

\section{DISCUSSÃO}

A formação de professores constitui-se em um processo de desenvolvimento pessoal e profissional. Contudo é imprescindível considerar os processos pelos quais eles se apropriam do conhecimento, as suas características pessoais, o seu conhecimento experiencial, profissional e assim valorizar os professores como sujeitos da sua formação.

Considerar o desenvolvimento profissional, pessoal e institucional mais além das práticas de formação e uni-lo a fatores não formadores, mas, sim, laborais, supõe uma reconceituação importante, já que não se analisa a formação apenas como o domínio das disciplinas e nem se centra nas características pessoais dos professores (IMBERNÓN, 2010, p. 82).

Numa sociedade marcada por crises políticas e discursos sobre as práticas escolares, muito mais da teoria do que da prática, na qual a elaboração das políticas e ou programas de formação continuada pouco tem dado importância das vozes dos professores, por outro, evidencia uma situação preocupante na prática associativa dos professores, as quais estão privadas do trabalho coletivo, consideradas arcaicas nos dias de hoje, no que se refere aos caminhos que a concepção de coletividade profissional poderia contribuir para diferentes direções, não só da profissão docente, como da escola.

Para ressaltar a importância das vozes dos professores, Nóvoa (2002, p. 48) afirma que:

É preciso dizer que, nesse processo de reconfiguração da profissão docente e de invenção de uma nova identidade profissional, a formação contínua ocupa um lugar decisivo. Os professores têm de abandonar uma atitude defensiva e "tomar a palavra" na construção do futuro da escola e da sua profissão.

O processo de formação do professor durante sua vida profissional, não se dá apenas em presenciar a palestras e cursos, mas em buscar a satisfação pessoal e profissional ao alicerçar sua profissão na produção de seus saberes e valores teóricos e práticos. Nesse sentido, Freire (2002, p. 19) conclui: "Assumir-se como ser social e histórico, como ser pensante, comunicante, transformador, criador, realizador de sonhos, capaz de ter raiva porque capaz de amar".

$\mathrm{Na}$ concepção do professor como um ser pensante, Josso (2006) aponta: “[...] porque a educação e formação são processos de transformação, múltiplos projetos que habitam, tecem, 
dinamizam e programam os relatos das histórias de vida e também informam sobre os desejos de ser e de vir a ser de seus autores".

Nessa perspectiva, considerando o professor e a construção da sua identidade, NÓVOA (1995, p. 25), enfatiza:

A formação deve estimular uma perspectiva crítico-reflexiva, que forneça aos professores os meios de um pensamento autônomo e que facilite as dinâmicas de autoformação participada. Estar em formação implica um investimento pessoal, um trabalho livre e criativo sobre os percursos e os projetos próprios, com vista à construção de uma identidade, que é também uma identidade profissional. O professor é a pessoa. E uma parte importante da pessoa é o professor (Nias, 1991). Urge por isso (re)encontrar espaços de interação entre as dimensões pessoais e profissionais, permitindo aos professores apropriar-se dos seus processos de formação e dar-lhes um sentido no quadro das suas histórias de vida. A formação não se constrói por acumulação (de cursos, de conhecimentos ou de técnicas), mas sim através de um trabalho de reflexividade crítica sobre as práticas e de (re)construção permanente de uma identidade pessoal. Por isso é tão importante investir a pessoa e dar um estatuto ao saber da experiência.

Para o processo de formação do professor, as práticas coletivas, construtivas e colaborativas, são necessárias na articulação da construção de saberes, pois compartilham erros e acertos e assim tornam formativos os valores envolvidos nesse processo.

Para que os professores ressignifiquem a sua prática é preciso que a teorizem. E este movimento de teorizar a prática não se efetiva somente com treinamentos, palestras, seminários, aulas expositivas, mas muito mais, quando há uma relação dinâmica com a prática deste professor a partir de uma reflexão coletiva, auto-reflexão, pensamento crítico e criativo, via educação continuada. É preciso desencadear estratégias de formação processuais, coletivas, dinâmicas e contínuas. Refletir com os demais professores e compartilhar erros e acertos, negociar significados e confrontar pontos de vista surge como algo estimulador para uma prática pedagógica comprometida. (RAUSCH e SCHLINDWEIN, 2001, p. 121).

As práticas coletivas e colaborativas tornam-se um fator importante e contribuinte para o processo de formação do professor, que terá a possibilidade de exercitar seu papel transformador e de autonomia.

\section{CONCLUSÃO}

Por meio deste estudo foi possível compreender a importância de considerar o professor como sujeito em sua própria formação e com identidade docente, num processo de auto formação e de reelaboração dos saberes iniciais. Saberes que vão se constituindo a partir de uma reflexão na e sobre a prática.

Os professores precisam ser vistos e ouvidos como sujeitos integrais e pensantes e não como objetos, considerando a sabedoria e experiência. O processo de formação do professor durante sua vida profissional, não ocorre apenas palestras e cursos, mas em buscar a satisfação pessoal e profissional ao alicerçar sua profissão na produção de seus saberes e valores teóricos e práticos. 
Nesse contexto, é necessário e imprescindível, a mudança e a inovação das práticas escolares, não mais como no princípio da racionalidade técnica, que estabelece como alguns princípios, a tarefa de alguns que pensam e outros que executam a prática docente.

Portanto, essa inovação e valorização, serão possíveis com a consciência da subjetividade dos professores, fazendo valer suas vozes, e desse modo passarão a serem sujeitos, protagonistas de sua formação.

As práticas coletivas, construtivas e colaborativas, são necessárias e de suma importância na articulação da construção de saberes e para o processo de formação do professor.

Contudo, o professor ao tornar-se sujeito no processo de sua formação, está contribuindo para sua própria prática docente, que será refletido no processo de ensino e a aprendizagem de seus alunos.

\section{REFERÊNCIAS}

ANASTÁCIO, Maria Queiroga Amoroso. Pesquisa qualitativa: concepções e perspectivas. Educação em foco. Juiz de Fora: UFJF, v. 11, n. 1, p. 189-198, mai/ago 2006.

FREIRE, Paulo. Pedagogia da Autonomia: saberes necessários à prática educativa. 25a ed. Paz e Terra, 2002.

GATTI, Bernadete. A formação continuada de professores: a questão psicossocial. Cadernos de Pesquisa, n. 119, p. 191-204, jul. 2003.

GIL, A. C. Como elaborar projetos de pesquisa. 5. Ed. São Paulo: Atlas, 2010.

IMBERNÓN, F. Formação continuada de professores. Porto Alegre: Artmed, 2010.

JOSSO, M.C. Os relatos de histórias de vida como desvelamento dos desafios existenciais da formação e do conhecimento: destinos sócio-culturais e projetos de vida programados na invenção de si. In: SOUZA, E.C., ABRAHÃO, M.H.M.B. (orgs). Tempos, narrativas e ficções: a invenção de si. Porto Alegre/Salvador, EDIPUCRS/EDUNEB, 2006.

NÓVOA, A. Formação de professores e profissão docente. In: (Org.). Os professores e a sua formação. 2. ed. Lisboa: Dom Quixote, 1995. p.15-33.

. Formação de professores e trabalho pedagógico. Lisboa: Educa, 2002.

PIMENTA, S.G. Formação de professores: Identidade e saberes da docência. In: PIMENTA, S.G. (Org.) Saberes pedagógicos e atividade docente. São Paulo: Cortez, 1999.

RAUSC, R. B.; SCHLINDWEIN, L. M. As ressignificações do pensar/fazer de um grupo de professoras das séries iniciais. Contrapontos, Itajaí, v. 1, n. 2, p. 109-23, 2001.

SILVA, M.H.G.F. Saber docente: Contingências culturais, experenciais, psico-sociais e formação. In: Anais da 20a Anped, 1997 (disq.). 